\title{
Organizational Commitment: Re-structuring a Concept Crucial for Management and Leadership Using a Confirmatory Factor Analysis
}

\author{
Thomas Meixner
}

Mendel University, Department of Management and Economics, Brno, Czech Republic

\begin{tabular}{|c|c|}
\hline & ABSTRACT \\
\hline $\begin{array}{l}\text { Keywords: } \\
\text { Organizational commitment, } \\
\text { Employee commitment, } \\
\text { Confirmatory factor analysis, } \\
\text { Emotional commitment }\end{array}$ & $\begin{array}{l}\text { This paper aimed at answering the question, how the widely discussed concept of } \\
\text { organizational commitment can be clustered. Based on relevant literature on employee } \\
\text { commitment, a four-dimensional model of commitment was proposed. The proposed layers } \\
\text { included a rational, a behavioral, a normative and an emotional layer, with each of them } \\
\text { ranging from the lowest level of commitment - compliance - to the highest level, described } \\
\text { as internalization. In order to assess this assumed model, the approach of an empirical study }\end{array}$ \\
\hline $\begin{array}{l}\text { Received } \\
26 \text { July } 2020\end{array}$ & $\begin{array}{l}\text { leading up to a confirmatory factor analysis was chosen. Using a wide array of pre-existing } \\
\text { questionnaires, a set of items were generated in accordance with the proposed model and tested }\end{array}$ \\
\hline $\begin{array}{l}\text { Received in revised form } \\
06 \text { August } 2020 \\
\text { Accepted } \\
\text { 08 August } 2020 \\
\end{array}$ & $\begin{array}{l}\text { on a survey of } \mathrm{n}=300 \text { participants. Using a R-based confirmatory factor analysis, the proposed } \\
\text { factor structure was assessed in terms of its model fit. Analyses however suggest a two-factor } \\
\text { model, as only for emotional and behavioral commitment a satisfactory model fit could be } \\
\text { shown. An additionally conducted reliability analysis confirmed this result. Therefore, based }\end{array}$ \\
\hline & $\begin{array}{l}\text { discussion of the results, that only the factors emotional and behavioral commitment target } \\
\text { actually the relationship between employer and employee, whereas normative commitment } \\
\text { depends stronger on the personality and the values of the employee, while rational } \\
\text { commitment might be stronger connected to the overall (employment) market situation } \\
\text { Potential recommendations for practitioners are deducted from the findings and possible } \\
\text { approaches for future research are presented. }\end{array}$ \\
\hline
\end{tabular}

The present paper is concerned with the internal structure of organizational commitment or employee commitment. Organizational commitment is a construct discussed intensively since the 1970s (Steers, 1977). It gained attention, Steers (1977) argues, as both researchers and practitioners were seeking for ways to improve employee retention, effectivity and performance. The author 
argues that "[e]mployee commitment is important for several reasons" (Steers, 1977, p. 47). Employee commitment to the company, he summarizes, is more important in predicting employee performance than related measures such as employee satisfaction, which - however - is considered to be one of the antecedents of commitment. This is especially true for employee turnover, which is most strongly predicted by (a lack of) commitment. The general importance that contemporary research describes employees to have is often compared to actual human resource (HR) strategies, with a remark that there often is a big discrepancy between employees and their values on the one side and HR practices on the other side (Lester \& Kickul, 2001). Thus, it seems to be clearly understood that employees, their motivation and their commitment are highly relevant, although this does not always translate to actual treatment of employees.

However, authors such as Meyer and Allen (1991) also argue, while the general importance of organizational commitment is undebatable, the wide variety of different definitions and approaches towards measuring it makes the comparison of studies in this field more complicated than necessary. Different models measuring organizational commitment typically focus either on the level of commitment - thus on the question how strong the commitment of an employee towards the company is - or on the scope of the commitment. This is shown by models such as the one proposed by Meyer and Allen (1991) who differentiate between affective commitment, continuance commitment and normative commitment. This differentiation has been widely discussed in the scientific community and recently been used as the foundation for a model proposed by Wolf (2018) who differentiates between four layers of commitment: rational, behavioral, normative and emotional layer. While those layers are not separable from each other completely, they still measure unique aspects of employee commitment, as Wolf (2018) postulates. Commitment, the author further argues, can be directed towards the company, the assignment and tasks, the colleagues, and towards the leaders or superiors, with different layers being developed in varying intensity for each of these commitment directions.

Kelman (1958) discussed three general stages that describe the way attitudes can change. These stages are compliance, identification and internalization (Kelman, 1958). Compliance, the author argues, is the lowest stage of attitudinal or behavioural change, describing a behaviour that the individual "tends to perform [...] only under conditions of surveillance by the influencing agent" (p. 54). The intermediary stage of change is described as identification. In this stage, Kelman (1958) explains, the individual "tends to perform [...] only under conditions of salience of his relationship to the agent" (p. 54). Only in the third stage of commitment to a behavior or attitude, an individual shows a behavior "under conditions of relevance of the issue, regardless of surveillance or salience" (p. 54).

The current study seeks to address the question, in which regards throughout various measures of organizational commitment both the three dimensions of organizational commitment as proposed by Kelman (1958) and by Magdalena (2014) and the four layers of commitment as proposed by Wolf (2018). The author argues that these models are not mutually exclusive. Rather, they can supplement each other which would imply a very holistic model for measuring organizational commitment. Each of the layers of commitment (Wolf, 2018) should therefore be able to reach each of the three levels of organizational commitment as proposed by Magdelana (2014). The assumption is summarized in Figure 1. 

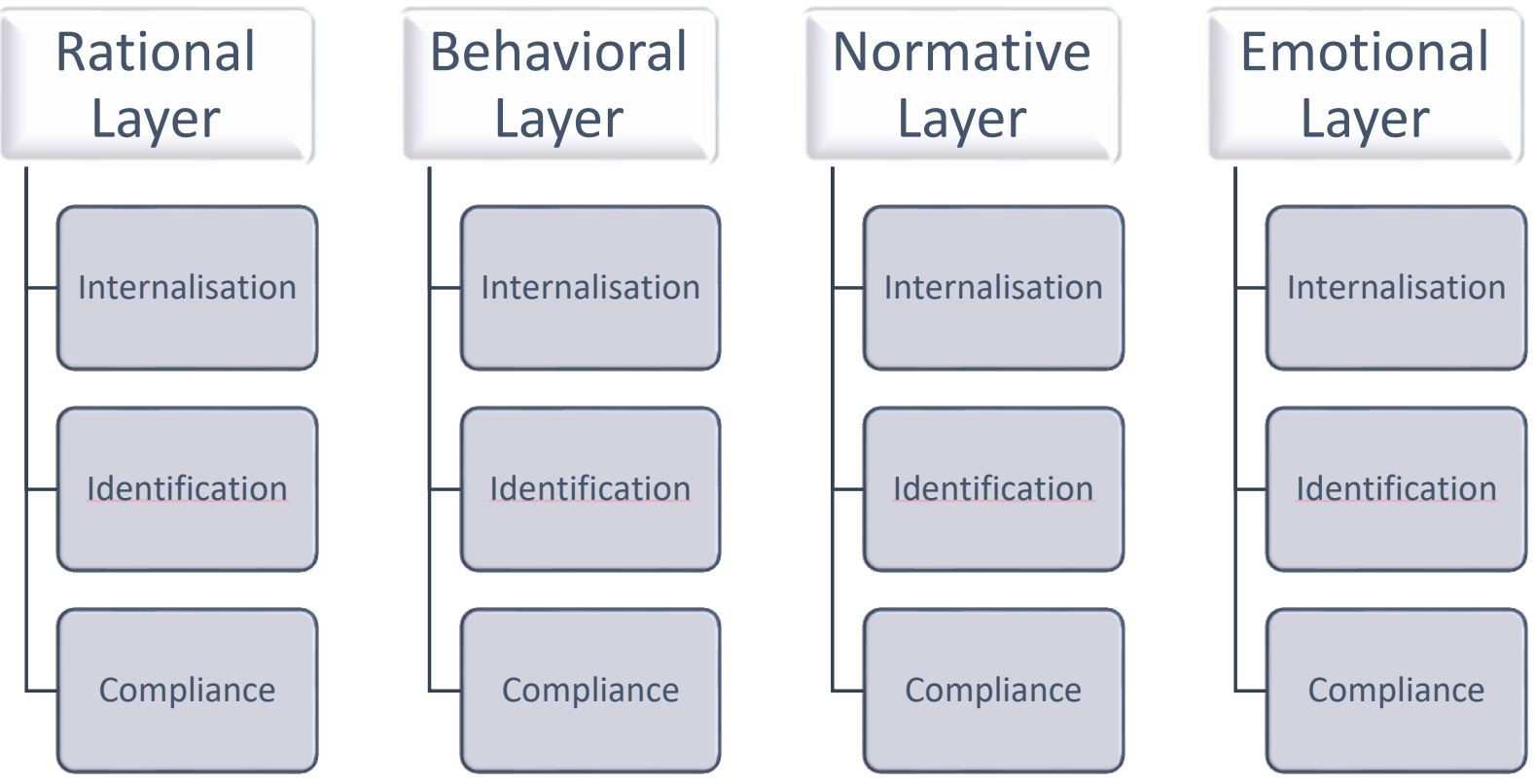

Figure 1. Proposed model of organizational commitment (own processing)

\section{State of Research}

\section{Employee Commitment and Engagement}

Market power relations are also changing in line with technological and social developments. A few decades ago, the sales market experienced a change from a seller's market to a buyer's market and now a change from an employer's market to an employee's market is underway (Wolf, 2014). It is becoming increasingly necessary for the continued existence of the company to recognize personnel as a differentiating factor and to retain employees because constantly changing personnel has a negative impact on service quality, customer satisfaction and customer loyalty (Wolf, 2014). As a result, the issue of long-term employee retention has become an inevitable success factor and a central component of corporate strategy (Felfe, 2008; Wolf, 2016). Authors such as Chambers, Foulon, Handfield-Jones, Hankin and Michaels (1998) even go one step further and speak of the war for talent, the ever-increasing search for talent and the question of how to retain it in the company long-term. The importance of this issue is also underlined by Bhattacharya, Sen and Korschun (2008), who make it clear that the employees of a company are one of the most important core resources and a success factor.

Becker, Billings, Eveleth and Gilbert (1996, p. 464) define organisational commitment as "the psychological attachment of workers to their workplace". As the authors explain, the commitment stands in connection to various positive outcomes, both for the company and the employees. Highly committed employees, the authors argue further, tend to have lower turnover-rates, tend to be more satisfied with their job and are thus, typically, more motivated to perform tasks given to them. They are generally viewed as more productive and less prone to making errors. This connection between employee commitment on the one hand and employee performance on the other hand, Becker et al. 
(1996) explain further, is heavily moderated by various factors such as personality, leadership style and motivation.

Especially, motivation is a factor often discussed in these regards. Heckhausen (1989) describes that performance motivation refers to behaviour that is related to a standard of proficiency. Accordingly, behaviour is performance motivated when a person strives to do something particularly well or better than others. An important aspect of performance motivation is, according to Heckhausen (1989), comparison, whereby this can be both comparison with others (for example with classmates or colleagues) and with one's own standards. Here the author mentions both past performances, i.e. the comparison with the performance of the previous year or with self-mentioned quality standards. According to Heckhausen (1989), it is important to note that these are selfimposed objectives, which clearly classifies performance motivation as part of intrinsic motivation.

As mentioned at the beginning, motivating employees is one of the core tasks of managers (Barling \& Beattie, 1983). One of the foundations of modern motivation research is the work of Ryan and Deci (2000). The authors distinguish between intrinsic and extrinsic motivation as the basis of human action (Ryan \& Deci, 2000). Motivation leads people to act, it gives them the necessary energy. It is not only possible to differentiate between different strengths of motivation, but also between their sources. This can either lie within the person and his or her values and goals or outside the person which leads to a division into intrinsic and extrinsic motivation. Intrinsic motivation therefore means to do something because it is inherently interesting or entertaining or satisfying (Ryan \& Deci, 2000), whereas extrinsic motivation describes behaviour that serves to achieve a goal. Extrinsic motivation is a construct that is always relevant when an activity is performed to achieve a separable result. Extrinsic motivation therefore stands in contrast to intrinsic motivation, where an activity is only performed for the pleasure of the activity itself and not for the benefit of the instrument. In contrast to some perspectives that view extrinsically motivated behavior as invariably non-autonomous, Ryan and Deci (2000) see that extrinsic motivation can vary greatly to the extent that it is autonomous.

Leadership behaviour can have effects on both intrinsic and extrinsic motivation (Barbuto, 2005). Intrinsic motivation in working life occurs when employees perform activities because they perceive them as meaningful, pleasant or satisfying. Extrinsic motivation occurs when activities are performed in order to achieve a goal or to receive a reward for doing so. It should be noted in this respect that in working or business life motivation is typically not purely intrinsic but rather represents a partial aspect of overall motivation (Barbuto, 2005). However, the fundamental aim of transformational leadership is primarily to strengthen intrinsic motivation, Barbuto (2005) was able to show this in an empirical study. Transactional leadership, on the other hand, clearly aims at strengthening extrinsic motivation, since it is based on a typical reward system (Barbuto, 2005). At the same time, however, the author also points out that motivation can only be created in part by managers: As the findings of the empirical study show, the leadership approach contributes only a comparatively small part to the clarification of motivation differences.

Felfe (2008), who devoted his research to employee satisfaction and retention, argues that satisfaction is typically strongly related to loyalty to the company. Thus, a high level of satisfaction in employees should go along with increased loyalty towards the company. The author further explains that this employee loyalty is not only an important factor for the company or organization but rather for the employee as well. By sensing a feeling of belonging to the company and a feeling 
of being bound to it, employees' so-called need for loyalty and recognition can also be strengthened. This feeling in turn should be experienced as positive by the employees, Felfe (2008) argues.

Based on this, Felfe (2008) and Felfe and Wombacher (2016) describe employee retention or commitment. They explain that their definition of commitment implies the psychological bond between the organisation or company on the one hand and the individual employee on the other hand (Felfe \& Wombacher, 2016). This commitment however, Felfe and Wombacher (2016) further explain, thereby agreeing with other experts in the field, is not a one-dimensional construct. It rather represents the interaction of multiple complex factors. The authors argue that commitment involves affective, calculative and normative aspects. Apart from this distinction the authors also argue that organisational commitment can vary based on the goal towards it is displayed. Commitment can not only be shown or experienced towards the organisation itself but also towards a leader, a team or a department.

\section{The Tri-dimensional Organizational Commitment Model}

The term commitment or organisation-related commitment refers to the subjectively experienced bond between an employee and his employer (Kanning, 2017). In this respect, an overlap between commitment and social identity in relation to the employer is to be expected, the author argues. However, this is not necessarily always the case. A bond can also exist beyond social identity if the employee has material advantages from belonging to an organization, for example, which he or she does not want to miss in the future. Such considerations led Allen and Meyer (1990) to a differentiation of forms of commitment which has found broad agreement in research, Kanning (2017) explains. Allen and Meyer (1990) differentiate in their influential work between three forms of commitment: Affective commitment refers to the emotional attachment of an employee to his employer. He or she feels joy or pride in belonging and is prepared to be loyal to his or her employer. The affective commitment, results such as those of Rodrigo, Aqueveque and Duran (2019) show, can strongly be influenced by the employer's activities, for example in the field of corporate social responsibility. The normative commitment is much more sober, Allen and Meyer (1990) explain. It is based on the conviction of being committed to the employer. For example, the employer has financed the training and paid the salary reliably for years which implies a certain obligation to stand behind this employer. If one would change companies at the first opportunity, for example because another company pays a higher salary or the current employer gets into financial difficulties, one would experience this as ungrateful and would have to expect to be "condemned" by other people. There is therefore a normative pressure for unity.

The three forms of commitment according to Allen and Meyer (1990) are correlated with each other. The more an employee is emotionally attached to his employer, the more likely he is to feel a normative-moral obligation to commit himself to that same employer. The correlation between normative and imputed commitment is much less pronounced. Wolf (2018) re-organized the existing aspects and introduced a fourth factor: Behavioural commitment. While a majority of commitment-related work mostly focuses on the attitudes employees hold towards their job and their employer, Wolf (2018) argues that actual behaviour also needs to be considered in order to make a complete model of organizational commitment: Whereas intentions and attitudes might be influential, actual behaviour might vary both in a positive or a negative way - employees with a high emotional bond might still be actively looking for other jobs whereas those with a low 
commitment might still not be on the lookout for reasons outside of the realm of commitment. In a similar vein, a link can be drawn towards scientific literature stemming from a different field - the field of health care. There, under the label of intention-behavior-gap it is discussed, that people sometimes tend not to follow their intentions when it comes to their actual behaviour. Due to factors such as convenience, people might not set actions although they do show the intentions to do so (Sheeran \& Webb, 2016).

There are many studies on commitment and subsequently also numerous meta-analyses. Two meta-analyses examine the connection between commitment and job satisfaction (Meyer et al., 2002; Tett \& Meyer, 1993), whereby in some cases very high connections are found which indicates a strong relationship between the two constructs. Meta-analyses examine the question of the extent to which relationships between commitment and professional performance can be proven (Cohen \& Hudecek, 1993; Cooper-Hakim \& Viswesvaran, 2005; Jaramillo, Mulki, \& Marshall, 2005; Meyer et al., 2002; Ng, 2015). Here, positive correlations can be found, especially for general and affective commitment. Commitment is thus generally recognized as a good predictor of a large number of entrepreneurial results, Kanning (2017) concludes.

\section{Objectives of the Study}

The goal of this empirical study is to explore the relationships of various measures of organizational commitment with each other and to answer the question, how far the proposed model of organizational commitment is reflected by existing measures. The proposed model sees four different layers of organizational commitment with three different levels of commitment in each layer. In order to answer this initial research question, an empirical approach is taken that is based on the measures, that will be described in the next section. These measures were presented to a sample of $n=300$ participants. Based on these responses a confirmatory factor analysis was conducted. As a first step for this factor analysis, the sum of all items derived from the measures described in the next section will be categorized based on the previously described theoretical assumptions. Therefore, a theoretical structure will form the foundation of the confirmatory factor analysis. This analysis will be conducted based on the answers of the 300 participants, thus assessing whether the theoretically proposed factor structure holds true for the empirical data. The results from this analysis will be used to describe the factors and layers found and to answer the research question, whether the theoretically proposed model of organizational commitment seems to apply. Therefore, the results will drive future research in the field by creating an empirically tested model of employee commitment. This model can be the foundation for future research in the field and open up new possibilities of analyses. The primary research question that should be answered within this work therefore is:

Can a model for measuring organizational commitment in a reliable way be developed based on existing material?

\section{Method}

\section{Sample and Data}

In order to assess the hypotheses of this work a sample of $n=300$ participants could be acquired, using a market research company's panel. The market research company used a random sample based on information presented about the target population: Business professionals with a minimum 
of five years of overall work experience, without limitation to specific fields or positions. Following this guideline, the company chose a total of $n=300$ participants out of their appropriate panel in order to obtain the data. Out of these 300 participants, $76.7 \%$ reported to be full-time employed, with another $21.7 \%$ being in part-time employment. The remaining $1.7 \%$ reported to be selfemployed. Table A1 in Appendix A shows the wide variety of fields in which the participants of the present study are active. A majority of participants (38\%) is employed in companies bigger than 500 employees (see Figure 2).

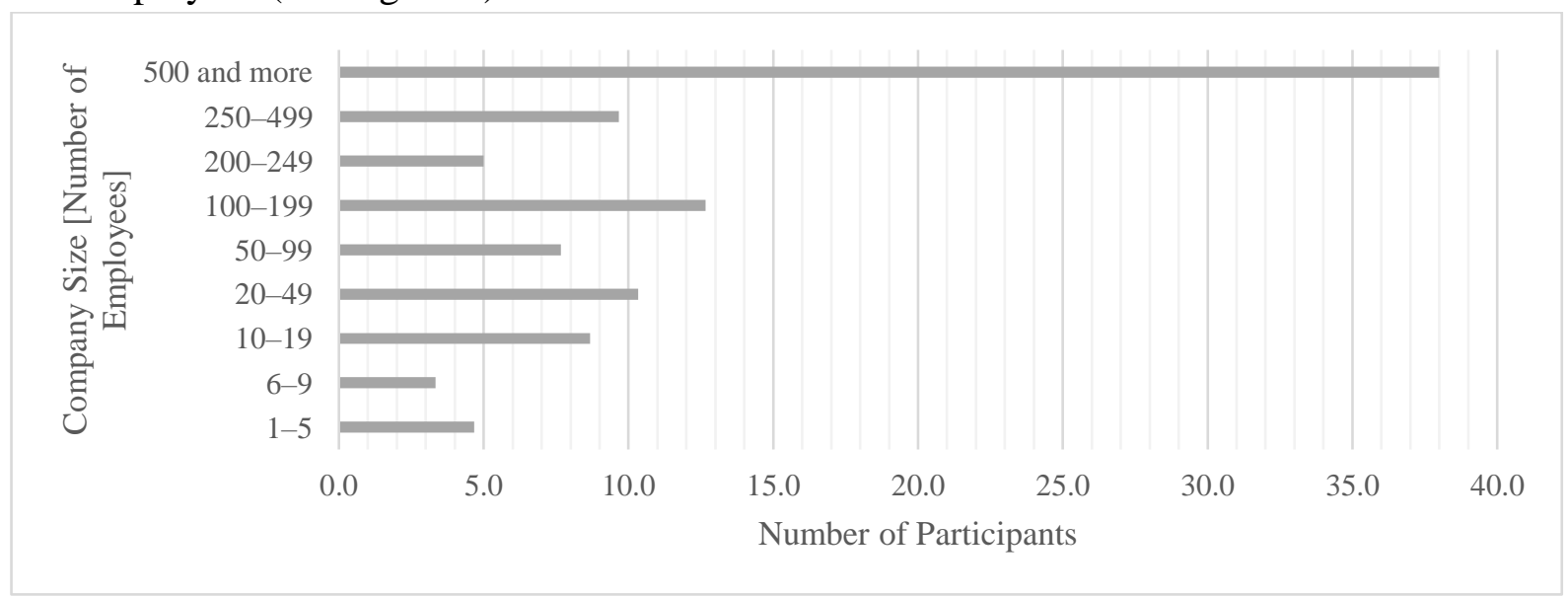

Figure 2. Company sizes of participants (own processing)

They have been on average for $M=8.16(S D=7.59)$ years with their current company and for around the same time $(M=8.055, S D=7.28)$ in the same field. $32.3 \%$ of participants reported to currently have managerial responsibility.

\section{Measures of Commitment Used in the Study}

The aim was to use a wide variety of different measures for organizational commitment in order to form a strong foundation for the factor analysis. Measures range from very established ones such as the Organizational Commitment Questionnaire (OCQ, Mowday, Steers, \& Porter, 1979) to lesser-known ones such as the scale presented by Irefin and Mechanic (2014). However, the focus was on finding measures that complement each other and in total represent the wide range of definitions and aspects of organizational commitment. The Work and Well-Being Survey (UWES) seems to be an outlier therein, that it measures organizational engagement which however, according to Schaufeli, Bakker and Salanova (2006), is a construct closely related to organizational commitment. A preliminary analysis of the items seems to indicate that the items have a strong focus on the behavioural and emotional aspects of employee commitment, as will be further described. These measures were accompanied by several sociodemographic measures and such in regards to work experience. The complete set of questionnaires and measures was presented to the participants using an online survey tool that allows for easy conduction.

\section{Organizational Commitment Questionnaire}

Based on the problem that a too wide variety of definitions in regards to organizational commitment seemed to exist, Mowday, Steers and Porter (1979) tried to develop a measure of organizational commitment that best combines the existing approaches. The authors therefore developed " 15 items that appeared to tap the three aspects of our definition of commitment" (p. 7). Mowday et al. (1979) 
used seven-point Likert scales for their items, ranging from "strongly agree" to "strongly disagree" (p. 7).

The authors conducted a validation study based on a sample of $n=2563$ employees in a wide variety of different jobs across 9 different companies. In order to assess the predictive validity of the OCQ, Mowday et al. (1979) used a wide variety of related measures, including various measures of job satisfaction, which they deemed a related concept. The internal consistency of the scale was analyzed using a factor analysis, item analysis and computation of the coefficient alpha. Alpha, which is a measure developed by Cronbach (1950), is an indicator for the internal consistency of a measure, ranging from .00 (indicating a complete lack of internal consistency) to 1.00 (indicating perfect consistency). The alpha values for the OCQ measure lay between .82 and .93 depending on the sub-sample used for the computation and are therefore well within the optimal levels as proposed by Cronbach (1950) or more recent works like the one of Tavakol and Dennick (2011). Mowday et al. (1979) conclude that the "results suggest the 15 items of the OCQ are relatively homogeneous with respect to the underlying attitude construct they measure" (p. 16). Satisfying results are also reported for the re-test reliability and for the predictive and convergent validity, with meaningful correlations being described to related measures.

\section{The Measurement and Antecedents of Affective, Continuance and Normative Commitment} Among others on the OCQ, Allen and Meyer (1990) developed a three-component measure for assessing organizational commitment. Based on the three-component model, their questionnaire measures the affective, continuance and normative commitment of employees towards their organization. In order to validate the model and the questionnaire derived from it, around 500 employees were assessed based on the 51 items the authors proposed for measuring the three components of organizational commitment and the additional 15 items derived from the OCQ. All items were based on seven-point Likert scales, following the same pattern as those of the OCQ. Based on factor analysis and an assessment of reliability (again, Cronbach's Alpha was chosen to be the criterion for assessing internal consistency of the scales) a total of 24 items were selected, spread evenly over the three sub-scales derived. Reliability estimates (Cronbach's Alpha) ranged from .75 to .89 , thus being again satisfactory results that imply appropriate reliability of the measure.

\section{Employee Commitment}

Irefin and Mechanic (2014) developed their measure of employee commitment based on criticism in regards to the OCQ and scales derived from the OCQ. The criticism Irefin and Mechanic (2014) are citing in these regards implies that the OCQ and measures derived from it do not actually (only) measure organizational commitment but rather also turnover intentions and performance intentions. These, however, are not to be considered a part of organizational commitment, the authors argue, but rather its consequence. Based on these assumptions, the authors developed a 15-item scale for measuring organizational commitment that separated the aspects of actual commitment and its consequences. Based on their empirical data, Irefin and Mechanic (2014) argue that their measure is a valid tool for assessing actual organizational commitment. 


\section{Results}

\section{Confirmatory Factor Analysis}

In order to assess the validity of the proposed model, a confirmatory factor analysis was computed using the statistical software R (R Core Team, 2017) and the statistical library LAVAAN for R (Rosseel, 2012) which was developed in order to provide the necessary functionality for computing confirmatory factor analyses and structural equation modelling.

Data was initially prepared using IBM SPSS 24 (IBM Corp, 2016), where descriptive statistics both for the description of the sample and for an initial overview of the data was prepared. In this step, items were also assessed for their item difficulty. Following the proposal of Andersen (1977), item difficulty was assessed in a first step to eliminate items that would not provide information, as they are either too easy (thus being solved by everyone) or too difficult (thus being solved by no one). However, item difficulties of all items within this study were in an appropriate range, which can be explained by the fact that only previously published items from validated measures were used for the present study. Therefore, item difficulty was already pre-assessed by the respective authors, shifting the focus of the current analysis away from an item-level analysis to a scale-level one.

The items derived from the measures and presented to the participants were in accordance with the definitions provided within this work clustered into the four relevant categories: emotional, rational, normative and behavioural. This resulted in the theoretical model presented below.

complete_model <- '

emot_factors = ACS_01 + ACS_02 + ACS_03 +ACS_04 + ACS_05 +ACS_06 + ACS_07 + ACS_08 + OCQ_05 + OCQ_06 + OCQ_08 + OCQ_10 + OCQ_12 + OCQ_13 + OCQ_14 + EC_01 + EC_02 + EC_05 + EC_13 + EC_14

rational_factors $=\sim$ CCS_01 + CCS_02 + CCS_03 + CCS_04 + CCS_05 + CCS_06 + CCS_07 + CCS_08 + OCQ_09 + OCQ_11 + OCQ_15

norm_factors $=\sim$ NCS_01 + NCS_02 + NCS_03 + NCS_04 + NCS_05 + NCS_06 + NCS_07 + $\mathrm{NCS} \_0 f a c t 8+\mathrm{EC} \_06+\mathrm{EC} \_10+\mathrm{EC} \_11+\mathrm{EC} \_12$

behav_factors = OCQ_01 + OCQ_02 + OCQ_03 + OCQ_04 + OCQ_07 + EC_03 + EC_04 + EC_07 + EC_08 + EC_09 + EC_15 + TC_01 + TC_02 + TC_03 + TC_04 + TC_05

all_factors $=\sim$ emot_factors + rational_factors + norm_factors + behave_factors

The equations presented above represent the individual factors and how they are assumed to contribute to the factors. The first factor tries to combine the emotional aspects of organizational commitment and is therefore derived from items describing these aspects. Subsequently, rational factors (rational_factors), normative aspects of commitment (norm_factors) and behavioral factors (behav_factors) are being described. Item names indicate the scale from which they were derived. ACC refers to the Affective Commitment Scale (Allen \& Meyer, 1990), CCS to the Continuance Commitment Scale (Allen \& Meyer, 1990), NCS to the Normative Commitment Scale (Allen \& Meyer, 1990), OCQ to the Organizational Commitment Questionnaire (Bozeman \& Perrewe, 2001) and EC to the Employee Commitment (Irefin \& Mechanic, 2014). All_factors represents the overall model consisting of the four proposed sub-scales (emotional, rational, normative, behavioral). 
The model defined like this formed the foundation for the first attempt of conducting the confirmatory factor analysis and depicts the assignment of the items from the various sources to the factors proposed by the theoretical model in this work. The factor all_factors is defined as the general factor over all factors, thus implying the overall factor organisational commitment, as defined by the model.

However, this first analysis showed only partially satisfying results, fit indices - as presented in Table 1 for the initial analysis - this is based on the overall model presented above and on modelling of the separate factors in separate analyses in order to assess for the low metric properties of the overall model.

Table 1

Various Fit Indices of Initial Model and Factors (Own Processing)

\begin{tabular}{llllll}
\hline & Overall & Emotional & Rational & Normative & Behavioral \\
\hline Chi-Square & 2916.75 & 531.01 & 116.09 & 166.60 & 330.04 \\
Df & 1171 & 170 & 44 & 54 & 104 \\
P-value (Chi-square) & .00 & .00 & .00 & .00 & .00 \\
Comparative Fit Index (CFI) & .72 & .87 & .63 & .50 & .66 \\
Tucker-Lewis Index (TLI) & .70 & .86 & .53 & .39 & .61 \\
RMSEA & .07 & .08 & .07 & .08 & .09 \\
\hline
\end{tabular}

The overall fit characteristics of the four sub-scales and the overall scale are depicted in Table 1 , displaying both the three aspects of the chi-square calculation (which will below be discussed in terms of their significance) and two measures of overall model fit - the Comparative Fit Index and the Tucker-Lewis Index. Both of these indicators are described to be of high relevance when assessing the quality of a structural model like the one derived from a confirmatory factor analysis (Cook, Kallen \& Amtmann, 2009, p. 449): "They estimate differences between the examined model and a hypothetical (null) model in which none of the components in the model are related." Also, the RMSEA (Root Mean Square Error of Approximation, see Browne \& Cudeck, 1993) is presented there as another fit index. It is assumed, that the overall fit of a model should be discussed not on single indicators but on the combination of a set of indices.

As the results presented in Table 1, the initially proposed model shows a poor fit - the result of the division of the Chi-Square value by the degrees of freedom results in a value of less than 3 $\left(\mathrm{Chi}^{2} / \mathrm{df}=2.49\right)$, with both the CFI and the TLI being lower than the optimal values of CFI $=.95$ and TLI $=.95$. A gaze towards the initial factors reveals, that especially the emotional factor seems to have an appropriate fit, with a $\mathrm{Chi}^{2} / \mathrm{df}=3.12$ and CFI and CLI values being above a threshold of .85. At least partially appropriate seem the results for the behavioural aspects, with a $\mathrm{Chi}^{2} / \mathrm{df}=3.17$ and a CFI $=.657$. While not an optimal fit, there at least seems to be a tendency towards a working model for these two factors. For the emotional and rational factors however, no such tendency can be observed: CFI and TLI indices are less than satisfactory and the proportion of Chi-Square and the degrees of freedom is lower than for the other factors for both of these factors (rational: $\mathrm{Chi}^{2} / \mathrm{df}$ = 2.63; normative: $\mathrm{Chi}^{2} / \mathrm{df}=3.07$ ).

In order to assess possible reasons for the poor fit of these two factors, a reliability analysis for both was conducted, assuming that low internal reliability might be a possible reason for the inappropriate fit measures. Cronbach Alpha was chosen as the measure for assessing internal reliability of the factors, assuming that the correlation of the individual item with the scale itself 
assesses how well the items fit the scale. In order to assess the internal reliability of the scales and to compute Cronbach Alpha as a measure of fit, the psych library for R (Revelle, 2019) was used. Based on the model described above Cronbach Alpha was computed for the four separate scales, as presented in Table 2.

Table 2

Reliability Analyses (Own Processing)

\begin{tabular}{lllll}
\hline & emotional & rational & normative & behavior \\
\hline Cronbach Alpha & .93 & .65 & .74 & .88 \\
\hline
\end{tabular}

In accordance with the explanations of Tavakol and Dennick (2011) in regards to the interpretation of reliability measures it is deducted that the reliability of both the rational and the normative factor are not satisfactory, which goes in alignment with the results found in the confirmatory factor analysis computed initially. Reliability analyses also provide insight not only on a scale level but also on an item level - one of the relevant information provided thereby is the question how Alpha would change if an individual item would be removed. This information was used to remove those items, whose removal would benefit the overall reliability of the scale. The scales thereby updated were used for another CFA, in order to assess whether the improvements actually lead to better and thus satisfactory results. Table 3 depicts the results for the individual scales in the repeated CFA, revealing slight improvements for the factors.

Table 3

Results of Second CFA after Elimination of Items with a Bad Fit (Own Processing)

\begin{tabular}{lllll}
\hline & Emotional & Rational & Normative & Behavioral \\
\hline Chi-Square & 483.52 & 60.65 & 57.59 & 197.20 \\
Df & 152 & 27 & 27 & 65 \\
P-value (Chi-square) & .00 & .00 & .00 & .00 \\
Comparative Fit Indiex (CFI) & .88 & .71 & .767 & .68 \\
Tucker-Lewis Index (TLI) & .86 & .61 & .69 & .61 \\
RMSEA & .09 & .06 & .06 & .08 \\
\hline
\end{tabular}

As shown in Table 3, a slight improvement due to the elimination of those items with a low fit can be observed for all factors, especially with regards to the proportion of Chi-Square value and degrees of freedom. However, especially for the rational scale still no satisfactory result can be shown, with a $\mathrm{Chi}^{2} / \mathrm{df}=2.24$. For the normative factor even a decline in fit can be observed, with a $\mathrm{Chi}^{2} / \mathrm{df}=2.13$. The proportion for the behavioural factor is, with $\mathrm{Chi}^{2} / \mathrm{df}=3.03$, still satisfactory. While the remaining fit indices are still not perfectly satisfactory overall the emotional and the behavioural factor will be chosen for further discussion, especially in regards to the satisfactory reliability of these two scales that could be improved for both of them.

\section{Description of Factors and Layers}

The results of the confirmatory factor analysis in combination with reliability analyses imply that the emotional and the behavioural factor as proposed by the theoretical model within this paper are the best fitting ones. While fit indices cannot be described as optimal, they seem to be in a satisfactory range. This is further supported by reliability measures for these scales which imply a very high reliability and thus a good fit of these scales. In order to also lay the gaze on the distinction 
between various levels of commitment - and not only on the factors - a descriptive depiction of the two factors is shown in Table 4 and Figure 3 and 4. Percentiles were formed for $33 \%$ and $67 \%$ in accordance with the assumption that three levels of organizational commitment exist.

Table 4

Description of Emotional and Behavioral Factor in Regards to the Sample (Own Processing)

\begin{tabular}{|c|c|c|c|}
\hline & & emotional_factor & behavioral_factor \\
\hline Mean & & 3.39 & 3.23 \\
\hline Std. Deviation & & .69 & .63 \\
\hline Minimum & & 1.37 & 1.08 \\
\hline Maximum & & 5.00 & 4.54 \\
\hline \multirow[t]{2}{*}{ Percentiles } & 33 & 3.11 & 3.00 \\
\hline & 67 & 3.79 & 3.56 \\
\hline
\end{tabular}

The distribution of the scale for emotional commitment is shown in Figure 3. The cut-off between the three levels of commitment lays at 3.105 for the lower cut-off and 3.789 for the upper cut-off with each of the three sections representing the same proportion of the sample.

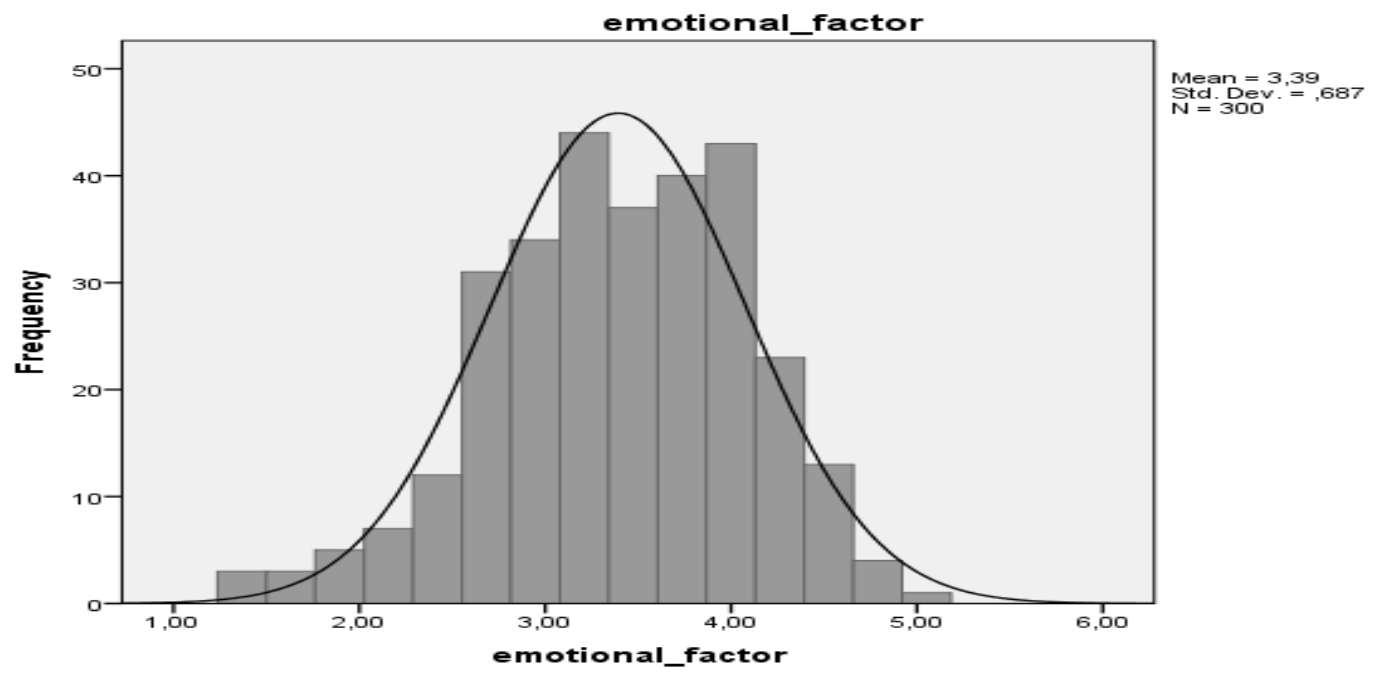

Figure 3. Emotional factor of organizational commitment - distribution (own processing)

Similarly, Figure 4 shows the distribution for the behavioral factor of organizational commitment.
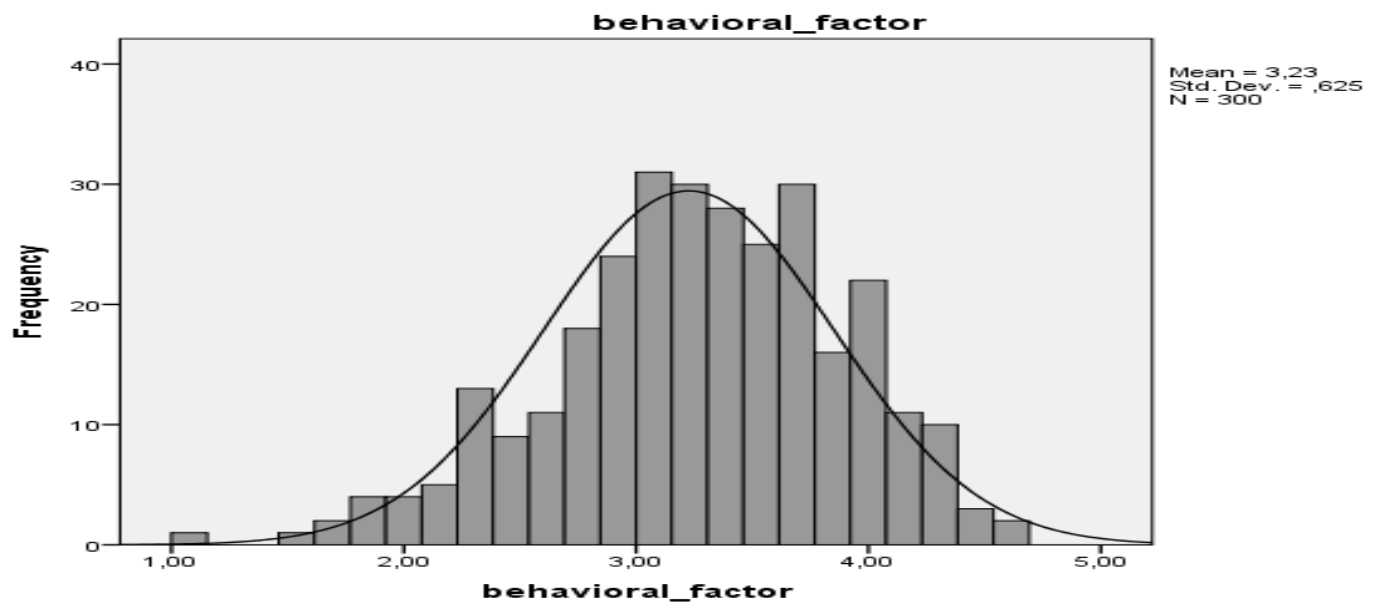

Figure 4. Behavioral factor of organizational commitment - distribution (own processing) 
This graphic depiction of the scales as well as the descriptive statistics presented in Table 4 are interpreted as indices for the overall fit of the scales as a distribution close to a standard distribution could be observed here. Following the curve of the standard distribution (see Figure 3 and 4), most values strongly group around the mean with an actual range spanning nearly the whole possible range. Cut-offs for the behavioral factor of organizational commitment are at 3.000 and at 3.538 respectively. Therefore, the initially proposed model could be partially confirmed; two out-off four factors could be confirmed based on a confirmatory factor analysis, and meaningful thresholds for separating the factors into three levels could be observed.

\section{Discussion}

The present study aimed to assess whether the model of organizational commitment proposed by Wolf (2018) can be confirmed based on empirical data. In order to assess the model, a literature review was conducted that helped to identify various measures of organizational commitment. This review revealed that measures for all four areas of organizational commitment as described by Wolf (2018) can be found within the scientific literature.

A selection of the vast amount of available measures was used to find out whether - when combined - the four different factors can be really identified within the resulting dataset. Based on a survey of $n=300$ participants - all of them with appropriate work experience - who assessed their own level of organizational commitment, a confirmatory factor analysis was computed that revealed that only for two of the factors an appropriate measurement seems to exist when focusing on the data: Only the factor emotional commitment and the factor behavioural commitment could be confirmed based on the various fit indices. The results for normative and rationale commitment were less satisfactory, even after an attempt to improve the model fit by adjusting for the lower reliability of these scales. However, the final conclusion of the present work is that not enough empirical evidence could be found for these two factors to assume their significance.

Thus, the levels of commitment (compliance, identification, internalisation) could also only be discussed for these two factors. Based on the current work, it is only partially possible to deduct why the remaining two factors (normative and rationale commitment) could not be confirmed. One possible conclusion, however, could be found in the very nature of these two aspects: Items concerning normative behaviour seemed to be based more strongly on personality, beliefs and values of a person than on the connection the person has towards the company. Items in regards to rationale commitment on the other side were also not really connected to the relationship with the company but rather with the connection with outside factors, such as the volatility of the employment market of the financial situation of the economy itself. Therefore, it can be argued that maybe these two factors - while still possibly relevant for the overall organizational commitment of a person - are less related to the actual relationship between employee and employer. This potential explanation is depicted in Figure 5 


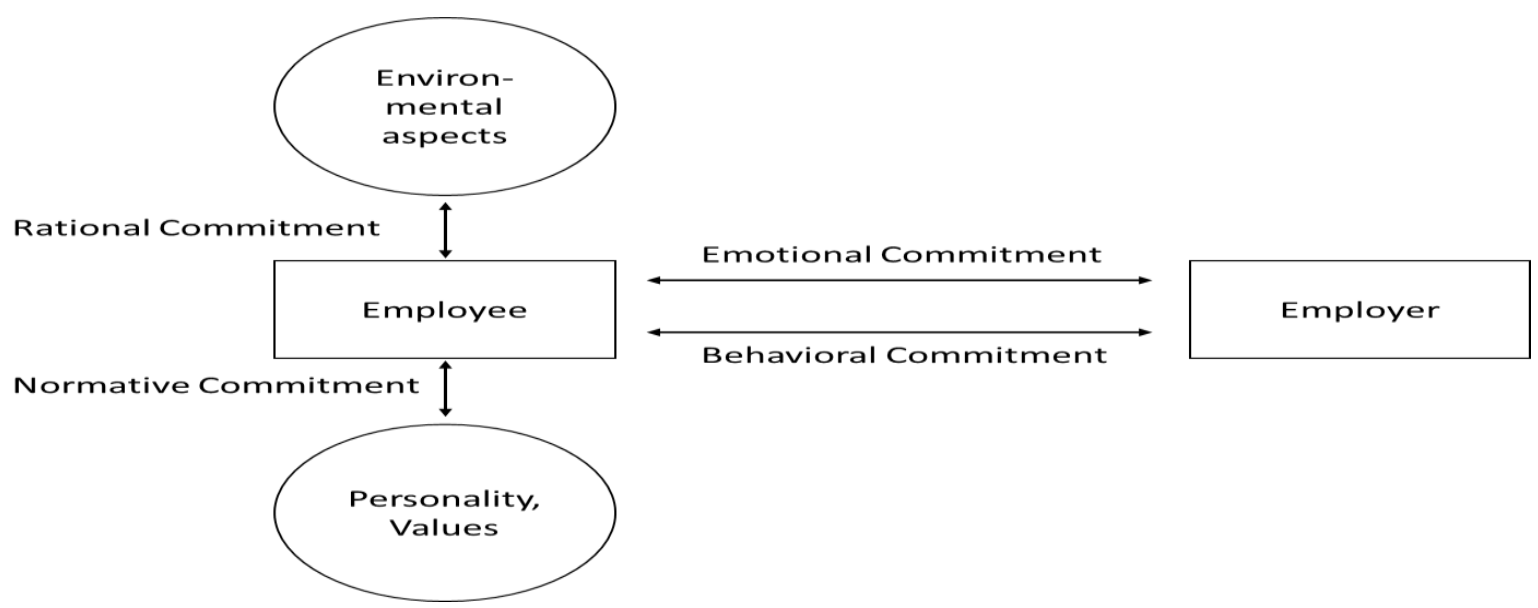

Figure 5. Final model of organizational commitment (own processing)

However, for further assessment of this assumption, additional empirical work will be necessary which will be able to assess additional variables necessary for fostering understanding whether the relationships proposed in Figure 5 are actually of statistical and, thus, factual significance.

Furthermore, future work will have to prove how various aspects of commitment influence employee's motivation, a factor crucial for many practitioners in the field. The assumption derived from the literature is that motivation is of course dependent on overall commitment, but it stands to be researched how the two aspects of emotional and behavioral commitment influence motivation in their own regards.

\section{Recommendations for Practitioners}

As a major recommendation for practitioners, the importance of relationship work between employer and employee can be deducted from the present work. While from a theoretical point of view, the utter importance of organizational commitment for an organization's long-term sustainable success could be shown again, the empirical part of this paper especially revealed the importance of emotional commitment between employer and employee. The model proposed in Figure 5 also hints towards the fact that only parts of organizational commitment can be strongly influenced by the employer. While normative commitment, thus, the tendency to believe that a long-term relationship between individual and organization is a positive aspect, might depend stronger on personality and values of the individual and while the rationale commitment seems to depend on environmental factors, the emotional connection can be influenced by the employer: Positive leadership communication, employee-oriented human resource management and leadership are factors identified within the scientific literature on the topic to be relevant predictors of commitment. Thus, an employer can of course try to improve rational commitment based on factors such as pay and benefits but will still be dependent on the environment - a volatile employment market might be leading employees to show stronger rational commitment to their current employer, whereas a less competitive market might do the opposite.

\section{References}

Allen, N. J., \& Meyer, J. P. (1990). The measurement and antecedents of affective, continuance and normative commitment to the organization. Journal of Occupational Psychology, 63(1), 1-18. 
Andersen, E. B. (1977). Sufficient statistics and latent trait models. Psychometrika, 42(1), 69-81.

Barbuto, J. E. (2005). Motivation and transactional, charismatic, and transformational leadership: A test of antecedents. Journal of Leadership and Organizational Studies, 11(4), 26-40.

Barling, J., \& Beattie, R. (1983). Self-efficacy beliefs and sales performance. Journal of Organizational Behavior Management, $5(1), 41-51$.

Becker, T. E., Billings, R. S., Eveleth, D. M., \& Gilbert, N. L. (1996). Foci and bases of employee commitment: Implications for job performance. Academy of Management Journal, 39(2), 464-482.

Bhattacharya, C. B., Sen, S., \& Korschun, D. (2008). Using corporate social responsibility to win the war for talent. MIT Sloan Management Review, 49(2), 36-44.

Bozeman, D. P., \& Perrewe, P. L. (2001). The effect of item content overlap on Organizational Commitment Questionnaireturnover cognitions relationships. Journal of Applied Psychology, 86(1), 161

Browne, M. W., \& Cudeck, R. (1993). Alternative ways of assessing model fit. In K. A. Bollen \& J. S. Long (Eds.), Testing structural equation models (pp. 136-172). Newbury Park, CA: Sage Publications.

Chambers, E. G., Foulon, M., Handfield-Jones, H., Hankin, S. M., \& Michaels III, E. G. (1998). The war for talent. The McKinsey Quarterly, 1(3), 44-58.

Cohen, A. \& Hudecek, N. (1993). Organizational commitment-turnover relationship across occupational groups. Group and Organizational Management, 18, 188-213.

Cook, K. F., Kallen, M. A., \& Amtmann, D. (2009). Having a fit: Impact of number of items and distribution of data on traditional criteria for assessing IRT's unidimensionality assumption. Quality of Life Research, 18(4), 447-460.

Cooper-Hakim, A. \& Viswesvaran, C. (2005). The construct of work commitment: Testing an integrative framework. Psychological Bulletin, 131, 241-259.

Cronbach, L. J. (1950). Further evidence on response sets and test design. Educational and Psychological Measurement, 10(1), 3-31.

Felfe, J. (2008). Mitarbeiterbindung. Göttingen: Hogrefe Verlag.

Felfe J., \& Wombacher J. (2016). Mitarbeiterbindung und Gesundheit. [Employee retention and health] In B. Badura, A. Ducki, H. Schröder, J. Klose, \& M. Meyer (Eds.) Fehlzeiten-Report 2016. Fehlzeiten-Report (Vielfalt managen: Gesundheit fördern Potenziale nutzen) [Missed times report 2016. Missed times Report (Managing diversity, fostering health - using potentials], vol 2016. Springer, Berlin, Heidelberg.

Heckhausen, H. (1989). Leistungsmotivation [Achievement Motivation]. In H. Heckhausen (Ed.), Motivation und Handeln [Motivation and Action] (pp. 231-278). Berlin: Springer.

IBM Corp. (2016). IBM SPSS Statistics for Windows, Version 24.0. Armonk, NY: IBM Corp.

Irefin, P., \& Mechanic, M. A. (2014). Effect of employee commitment on organizational performance in Coca Cola Nigeria Limited Maiduguri, Borno state. Journal of Humanities and Social Science, 19(3), 33-41.

Jaramillo, F., Mulki, J. P., \& Marshall, G. W. (2005). A meta-analysis of the relationship between organizational commitment and salesperson job performance: 25 years of research. Journal of Business Research, 58, 705-714.

Kanning U. P. (2017). Grundlagen der Mitarbeiterbindung. [Foundations of employee retention] In U. P. Kanning (Ed.), Personalmarketing, employer branding und mitarbeiterbindung [Personnel marketing, employer branding and emplyee retention] (pp. 191-216). Berlin: Springer.

Kelman, H. C. (1958). Compliance, identification, and internalization three processes of attitude change. Journal of Conflict Resolution, 2(1), 51-60.

Lester, S. W., \& Kickul, J. (2001). Psychological contracts in the 21st century: What employees value most and how well organizations are responding to these expectations. People and Strategy, 24(1), 10.

Magdalena, S. M. (2014). The effects of organizational citizenship behavior in the academic environment. Procedia-Social and Behavioral Sciences, 127, 738-742.

Meyer, J. P., \& Allen, N. J. (1991). A three-component conceptualization of organizational commitment. Human Resource Management Review, 1(1), 61-89.

Meyer, J. P., Stanley, D. J., Herscovitch, L., \& Topolnytsky, L. (2002). Affective, continuance, and normative commitment to the organization: A meta-analysis of antecedents, correlates, and consequences. Journal of Vocational Behavior, 61, $20-52$.

Mowday, R. T., Steers, R. M. \& Porter, L. W. (1979). The measurement of organizational commitment. Journal of Vocational Behavior, 14, 224-247. 
Ng, T. W. H. (2015). The incremental validity of organizational commitment, organizational trust, and organizational identification. Journal of Vocational Behavior, 88, 154-163.

R Core Team (2017). R: A language and environment for statistical computing. Wien: R Foundation for Statistical Computing. URL: https://www.R-project.org/.

Revelle, W. (2019). psych: Procedures for Psychological, Psychometric, and Personality Research. Evanston: Northwestern University. URL: https://CRAN.R-project.org/package=psych.

Rodrigo, P., Aqueveque, C., \& Duran, I. J. (2019). Do employees value strategic CSR? A tale of affective organizational commitment and its underlying mechanisms. Business Ethics: A European Review, 28(4), 459-475.

Rosseel, Y. (2012). Lavaan: An R package for structural equation modeling and more. Version 0.5-12 (BETA). Journal of Statistical Software, 48(2), 1-36.

Ryan, R. M., \& Deci, E. L. (2000). Intrinsic and extrinsic motivations: Classic definitions and new directions. Contemporary Educational Psychology, 25(1), 54-67.

Schaufeli, W. B., Bakker, A. B., \& Salanova, M. (2006). The measurement of work engagement with a short questionnaire: A cross-national study. Educational and Psychological Measurement, 66(4), 701-716.

Sheeran, P., \& Webb, T. L. (2016). The intention-behavior gap. Social and Personality Psychology Compass, 10(9), 503-518.

Steers, R. M. (1977). Antecedents and outcomes of organizational commitment. Administrative Science Quarterly, 22(1), 46-56.

Tavakol, M., \& Dennick, R. (2011). Making sense of Cronbach's alpha. International Journal of Medical Education, 2, 53-55.

Tett, R. P., \& Meyer, J. P. (1993). Job satisfaction, organizational commitment, turnover intention, and turnover: Path analysis based on meta-analytic findings. Personnel Psychology, 46, 259-293.

Wolf, G. (2014). Mitarbeiter anziehen, motivieren, binden: Emotionen entscheiden. Service Today, 3, 14-17.

Wolf, G. (2016). Mitarbeiterbindung. Strategie und Umsetzung im Unternehmen (2. Aufl.). [Employee retention: Strategies and implication in the organization, $2^{\text {nd }}$ Edition]. Freiburg: Haufe-Lexware.

Wolf, G. (2018). Mitarbeiterbindung: Strategie und Umsetzung im Unternehmen (3. Aufl.). [Employee retention: Strategies and implication in the organization, $3^{\text {rd }}$ Edition] Freiburg: Haufe-Lexware.

\section{Appendix}

Table A1

\begin{tabular}{lll}
\hline & Frequency & Percent \\
\hline Agriculture, Forestry, Fishery & 2 & .7 \\
Mining and Quarrying & 1 & .3 \\
Manufacturing & 26 & 8.7 \\
Energy Supply/ Electricity, Gas, Steam and & 8 & 2.7 \\
Air Conditioning & & \\
Water Supply; Sewerage, Waste & 1 & .3 \\
Management and Remediation Ser & 5 & \\
Construction & 19 & 1.7 \\
Wholesale and Retail Trade & 2 & 6,3 \\
Repair/ Maintenance of Motor Vehicles and & & .7 \\
Motorcycles & 23 & \\
Transportation and storage & 7 & 7,7 \\
Accommodation and Food Services & 36 & 2.3 \\
Information and Communication & 27 & 12.0 \\
Financial and Insurance Services & 3 & 9.0 \\
Real Estate Services & 15 & 1.0 \\
Freelance Professional, Scientiefic and & & 5.0 \\
Technical Services & 20 & \\
Administrative and Support Services & 22 & 6.7 \\
Public Administration and Defence & 24 & 7.3 \\
Education & 17 & 8.0 \\
Social Work & 21 & 5.7 \\
Human Health Services & 12 & 7.0 \\
Arts, Culture and Entertainment & 3 & 4.0 \\
Recreation/ Sports Services & 6 & 1.0 \\
Other & 300 & 2.0 \\
Total & & 100.0 \\
\hline
\end{tabular}

